136 | Japanese Language and Literature

Asako, philosophers like Asada Akira, and sociologists like Miyadai Shinji, Makino Tomokazu, and Kurita Nobuyoshi, are a definite boon to the field of Japan studies.

Much like Sadako's cursed videotape in the Ring franchise, my immediate reaction upon finishing The Monstrous-Feminine in Contemporary Japanese Popular Culture was to share it with everyone I knew, as the most exciting scholarly monograph on contemporary Japanese horror to date.

\title{
Danwa to Purofishienshĩ: Sono shin no sugata no tankyū to kyōiku jissen o mezashite (Discourse and Proficiency: Aiming for Pursuit of Truth and Educational Practice) 談話とプロフィシ エンシー その真の姿の探求と教育実践をめざして
}

Edited by Osamu Kamada, Kazuko Shimada, and Ryoichi

Tsutsumi. Tokyo: Bonjinsha, 2015. iv, 238 pp. ¥2,600.

\section{Reviewed by}

Yumiko Kawanishi

Danwa to Purofishienshī: Sono shin no sugata no tankyū to kyōiku jissen o mezashite (hereafter Discourse and Proficiency) aims to provide crucial insights about actual language use in Japanese and instill the concept of discourse in Japanese language education. Kamada presents the definition of proficiency in the ACTFL OPI Tester Training Manual (Swender and Vicars 2012: 2) as "a degree" of "functional language ability - the ability to use a foreign language effectively and appropriately in real life setting." He defines discourse as any linguistic activity that occurs in context and suggests that shedding light on discourse is an important step towards improving learners' proficiency in Japanese language education. Throughout the whole volume, various teaching ideas are provided for actual classroom instruction. The entire book is written in Japanese.

Discourse and Proficiency consists of three main parts. Part I ("New Perspectives on Discourse") contains three chapters; each one reminds readers that discourse in real life is dynamic and complicated by showing how linguistic expressions and communicative behavior such as filler, discourse markers, and disfluency contribute to successful 
communication. Part II ("Research Based on New Perspectives on Discourse") consists of another three chapters, which variously deal with recent studies on specific expressions such as sonna kanji (something like that), pragmatic particles $n e$ and yo, and written discourse of e-mail requests. Finally, Part III ("New Perspectives on Discourse and Reality in the Classroom") is comprised of a single chapter by Shimada, who calls for the need of discourse-oriented instruction from the beginning level. These three main parts are followed by a transcript of a round-table discussion among three of the contributing authors of the book; they touch on such topics as the relationships between fillers and proposition, the notion of nativity, and assessment.

In chapter 1 ("True Taboos and False Taboos in Japanese Communication"), the author Sadanobu points out that our understanding of "preferable communication patterns" are at variance with those in reality. He introduces and examines "taboos" (or misunderstandings) of communication in Japanese contexts, and consideration of them, he suggests, can improve Japanese instruction. Sadanobu defines "taboos" as linguistic behavioral patterns that are to be avoided as they are viewed as the complete opposite of what we view as "good communication" (8), and he suggests that there are false taboos and true taboos. "False taboos" include (1) disfluent utterances, (2) overlapping utterances, and (3) utterances made without a cheerful tone or facial expression. He claims that while these kinds of utterances are often avoided in Japanese language class, in reality they can perform very significant roles that help students produce smooth and effective communication, especially when achieving such speech acts as declining an invitation and denying others' humble remarks. Sadanobu also discusses "true taboos" in Japanese communication. For example, showing off how fluently one can speak a foreign language is one of the true taboos, and in some cases disfluent utterances and a solemn tone may serve as effective strategies towards successful communication. He points out that manipulative use of features of so-called good communicative behavior can even undermine one's reputation as a good communicator. He concludes his chapter by suggesting there is great potential in interaction outside of class where learners of Japanese develop various communicative features that help them become so-called good communicators in Japanese.

In chapter 3 ("Thinking the ACTFL-OPI Guidelines Critically Through the Lens of Discourse"), Shimizu critically analyzes the ACTFLOPI guidelines based on the definition of discourse that is an utterance 
138 | Japanese Language and Literature

issued in a specific context. He also offers his view of pragmatics. He points out that in the ACTFL-OPI assessment criteria, there is a tendency to focus on the skills that convey information and carry out a task or function effectively, such as accuracy and fluency. Shimizu therefore argues that the criteria overlook (1) interpersonal skills including the use of disfluency in order to show consideration for others (in asking for a consultation, for example), and, (2) how we convey information not only effectively but also "smoothly" 円滑に (enkatsu ni). Shimizu suggests further refinement of the ACTFL-OPI assessment criteria especially in the areas of pragmatic and sociolinguistic accuracy.

Part II consists of three papers that present research findings based on the new concepts of discourse discussed in Part I. In chapter 5 ("Proficiency and ' $\mathrm{Ne}$ ' and ' $\mathrm{Yo}$ "'), Saigo points out that the pragmatic particles $n e$ and $y o$ are both indispensable to carry out smooth conversations in Japanese; thus, it is crucial to teach them in order to raise learners' proficiency levels in Japanese. By quoting earlier studies on the pragmatic particles, Saigō conducts textbook analyses and shows that dialogues in elementary level textbooks lack these pragmatic particles, making them unnatural. In order to improve the learning environmentincluding textbooks, learning materials, and teachers' input-and to have more realistic linguistic interactions than what is present in currently available materials, Saigō argues that instructors should not always follow the sequence of IRF or IRE ( $\mathrm{I}=$ initiation by instructor, $\mathrm{R}=$ response by learner, $\mathrm{F}=$ feedback by instructor, $\mathrm{E}=$ evaluation by instructor). Rather, they should let the learners take the initiative of carrying out conversations instead of passively replying to instructors' questions. While both ne and yo have procedural functions in discourse similar to "you know" in English, in that the particles help the interlocutor arrive at an appropriate interpretation of the utterance (Blakemore 1987, cited in Saigō), Saigō points out that there are occasions, such as in Kyoo wa tenki ga ii desu, in a conversation between two people where the lack of ne sounds unnatural because the particle is necessary to indicate that an utterance is directed to the interlocutor. Using some actual conversational data, Saigō shows that $n e$ is used to establish a common ground between two speakers in a conversation where the speaker has the intention to develop the conversation into a speech act of invitation. Similarly, yo is used to move the conversation forward or to express the speaker's intention not to finish the current topic. Saigo claims that it is necessary to have more holistic perspectives of discourse (including pragmatic particles ne and yo in 
classroom conversations) in order to improve our learning environments for learners.

Whereas all chapters up to chapter 5 are mainly concerned with spoken discourse, Yui in chapter 6 ("Discourse and Proficiency in Writing") discusses proficiency in written discourse. Focusing on speech acts of making a request and declining a request via e-mail, she analyzes sample e-mail messages written by Japanese native speakers, advanced learners, and intermediate learners. What she found was that advanced learners' messages are similar to those of native speakers in that they used deictic expressions indicating their awareness of their interlocutor with whom they share time and space. She also found that more advanced learners utilized linguistic expressions appropriate for the situation of declining, and she argues that it shows they developed a schema, i. e., a set of knowledge about expressions associated with a situation. Her study reminds us that language proficiency is not only for speaking but also for all four skills including written communication.

Shimada's chapter ('Educational Practice Aimed at Nurturing Discourse Skills: Discourse-Oriented Instruction from Beginning of Elementary Levels") advocates that discourse-oriented instruction should be implemented in Japanese education. This chapter offers some teaching ideas with concrete examples. Shimada contends that instructors should present realistic and practical models in interaction that contain fillers and pragmatic particles even from the beginning level. She also suggests that instructors should encourage their students to produce longer utterances than a single sentence, to get them to expand the conversation by providing follow up questions so that their communication goes beyond a short question-and-answer sequence.

As the authors demonstrate in their volume, actual spoken discourse is full of particular features serving for interactional needs, such as pragmatic particles ( $n e, n \bar{e}, y o$ ), response tokens ( $n n, \bar{e})$, a filler (ano), discourse markers (nanka, $m \bar{o}$ ), and they are viewed as crucial elements of discourse grammar, as in the multiple-grammar model described in Iwasaki's article, "A Multiple-Grammar Model of Speakers' Linguistic Knowledge" (Cognitive Linguistics 26:2). Authors such as Saigō and Shimada successfully demonstrate that currently available materials for the elementary level do not adequately capture some of the crucial features that make communication effective and appropriate. Some of those features can easily be incorporated into classroom instruction as shown in this volume. For example, teachers can introduce how to express the 
140 | Japanese Language and Literature

speaker's hesitation to decline an offer (pointed out by Sadanobu and Shimizu in the volume as "being disfluent") in order to show his/her consideration for the interlocutor. Another example is that the combination of no da and ne/yo, which as Saigō points out, can be introduced to practice conversation in which one tells a short story. Although it is important to instruct and guide learners with materials and language appropriate for the learners' level, instructors should include in their lessons the crucial features that make discourse coherent, cohesive, and effective as communication. Discourse and Proficiency successfully provides instructors with multiple ways to improve learners' proficiency in Japanese.

This volume urges instructors to apply the new perspectives on discourse in their Japanese language instruction from the very beginning in the elementary-level classrooms by reviewing the materials as a part of their day-to-day classroom interactions. Even though it is challenging to teach and guide learners to acquire the skills and knowledge so they can deal with dynamic and real conversational flow, Discourse and Proficiency can be used as resource to help instructors reach these goals in their classrooms. Discourse and Proficiency also reminds us of the constant need for us to go beyond survival level communication in our teaching.

\section{Ecocriticism in Japan}

Edited by Hisaaki Wake, Keijiro Suga, and Yuki Masami. New York: Lexington Books, 2018. 296 pp. \$90.00.

\section{Reviewed by Carin Holroyd}

For a scholar outside the field of ecocriticism, it is somewhat surprising to discover how much this is a contested terrain. The intersections of ecology, ecological understanding, culture and national/regional values have created remarkable intellectual diversity and substantial debate about the potential for academic unity in the area. This substantial and fascinating collection, Ecocriticism in Japan, is dedicated to the search for a Japanese conceptualization of ecocriticism. The work differentiates between 